\title{
Treadmill running restores MDMA-mediated hyperthermia prevented by inhibition of the dorsomedial hypothalamus
}

\author{
Dmitry V Zaretskya ${ }^{\mathrm{a}}$, Maria V Zaretskaia ${ }^{\mathrm{a}}$, Pamela J Durant ${ }^{\mathrm{a}}$, and Daniel E Rusyniak ${ }^{\mathrm{a}, \mathrm{b}}$ \\ aDepartment of Emergency Medicine, Indiana University School of Medicine, Indianapolis, \\ Indiana, USA \\ bepartment of Pharmacology and Toxicology, Indiana University School of Medicine, \\ Indianapolis, Indiana, USA
}

\begin{abstract}
The contribution of exercise to hyperthermia mediated by MDMA is not known. We recently showed that inhibiting the dorsomedial hypothalamus (DMH) attenuated spontaneous locomotion and hyperthermia and prevented deaths in rats given MDMA in a warm environment. The goal of this study was to confirm that restoring locomotion through a treadmill would reverse these effects thereby confirming that locomotion mediated by the DMH contributes to MDMA-mediated hyperthermia. Rats were randomized to receive bilateral microinjections, into the region of the DMH, of muscimol (80 pmol/100nl) or artificial CSF followed by a systemic dose of either MDMA $(7.5 \mathrm{mg} / \mathrm{kg}$, i.v.) or saline. Immediately after the systemic injection, rats were placed on a motorized treadmill maintained at $32^{\circ} \mathrm{C}$. Rats were exercised at a fixed speed $(10 \mathrm{~m} / \mathrm{min})$ until their core temperature reached $41^{\circ} \mathrm{C}$. Our results showed that a fixed exercise load abolished the decreases in temperature and mortality, seen previously with inhibition of the DMH in freely moving rats. Therefore, locomotion mediated by neurons in the DMH is critical to the development of hyperthermia from MDMA.
\end{abstract}

\section{Keywords}

MDMA; hyperthermia; heat stroke; locomotion; dorsomedial hypothalamus

\section{Introduction}

Deaths involving the drug 3,4-methylenedioxymethamphetamine (MDMA) often occur at dance parties where the ambient temperature may be elevated, and users commonly engage

\footnotetext{
(C) 2015 Published by Elsevier B.V.

Corresponding author: Daniel E. Rusyniak, MD, Professor of Emergency Medicine, 720 Eskenazi Ave, $3^{\text {rd }}$ floor $5^{\text {th }} / 3^{\text {rd }}$ Faculty Office Building, Indianapolis, IN 46202, Phone: (317) 880-3900, Fax: (317) 313-6369, drusynia@iu.edu.

Publisher's Disclaimer: This is a PDF file of an unedited manuscript that has been accepted for publication. As a service to our customers we are providing this early version of the manuscript. The manuscript will undergo copyediting, typesetting, and review of the resulting proof before it is published in its final citable form. Please note that during the production process errors may be discovered which could affect the content, and all legal disclaimers that apply to the journal pertain.

Disclosures

No conflicts of interest, financial or otherwise, are declared by the authors.
} 
in vigorous exercise. Previous research has shown that exercise increases the toxicity and hyperthermia of MDMA $(1,2)$ but despite this, locomotion and exercise have been discounted as major contributors to hyperthermia from MDMA. If locomotion is a major contributor to heat-related deaths from MDMA, then understanding how stimulants evoke locomotion and allow persons to exert themselves to the point of heat stroke is an important step in developing prevention strategies.

We have previously shown that inhibiting neurons in the region of the dorsomedial hypothalamus $(\mathrm{DMH})$ attenuates spontaneous locomotion, hyperthermia, and prevents mortality in rats given MDMA in a warm environment (3). Interestingly, inhibiting neurons in the region of the DMH had no effect on increases in brown adipose tissue (iBAT) thermogenesis, or on decreases in cutaneous blood flow mediated by MDMA (3). This suggests that locomotion may by itself be a significant contributor to the development of hyperthermia from MDMA.

The DMH, however, is involved in numerous physiologic processes that might also contribute to hyperthermia from MDMA: shivering (4), stress-evoked increases in heart rate and adrenocorticotropic hormone (5), and behavioral thermoregulation (6). Although there is a correlation between decreases in locomotion and decreases in hyperthermia from MDMA, it is unknown if it is locomotion or another effect produced by neurons in the DMH that contributes to hyperthermia from MDMA.

The objective of this study was to confirm that locomotion mediated by the DMH is an important contributor to hyperthermia from MDMA given to rats in a warm environment. To do this we used treadmills to isolate and control the amount of locomotion produced by rats given MDMA. We hypothesized that decreases in MDMA-mediated hyperthermia and mortality seen previously with inhibition of the DMH, would be abolished when locomotion was restored using a treadmill in DMH-inhibited rats given MDMA in a warm environment.

\section{Results}

\subsection{Temperature curves}

Running at an ambient temperature of $32^{\circ} \mathrm{C}$ quickly increased the body temperature of rats (Fig.1A). Independent of their group, all the rats reached body temperatures of $41^{\circ} \mathrm{C}$ by 40 minutes. Rats who injected with MDMA (aCSF/MDMA and muscimol/MDMA), however, reached critical temperatures 16 min faster $(p<0.05)$ than rats given saline (aCSF-Saline and Muscimol/Saline groups). There were no differences within the Saline or MDMA groups. This is in contrast to our previous paper where we showed that inhibiting the DMH significantly decreased the temperature of MDMA-treated rats (3). Therefore equalizing the amount of locomotion between groups of rats treated with MDMA reverses the temperature effects seen with inhibiting the DMH.

\subsection{Heat accumulation}

MDMA, compared to saline, also increased the rate of heat accumulation (Fig.1B). There were no differences within groups given MDMA (aCSF/MDMA vs. Musc/MDMA) or within groups given Saline (aCSF/Sal vs Musc/Sal). Furthermore, this data shows that of the 
individual contributions to heat accumulation in rats treated with MDMA locomotion accounts for $\sim 50 \%$. The other half is likely the combination of impaired heat dissipation (through vasoconstriction) and non-shivering thermogenesis (through iBAT).

\section{Discussion}

When viewed in light of our previous work, the findings of this study demonstrate that decreases in the MDMA-mediated hyperthermia seen after inhibition of neurons in the $\mathrm{DMH}$ are due to reductions in locomotion.

In two previous papers we showed that inhibiting neurons in the DMH decreased spontaneous locomotion and hyperthermia produced by MDMA $(3,7)$. It was not known, however, if decreases in locomotion were the cause of attenuated temperatures or merely associated with them. As we show in this paper, restoring locomotion in DMH-inhibited rats also restores hyperthermia thereby confirming locomotion as a significant contributor to MDMA-mediated hyperthermia. It is important to note that non-locomotor effects are also important contributors to hyperthermia mediated by MDMA. The differences $\left(\sim 0.1^{\circ} \mathrm{C} / \mathrm{min}\right)$ in the rate of heat accumulation between rats given MDMA and saline (Fig. 1B) are likely from non-locomotor contributions to heat accumulation such as iBAT thermogenesis and cutaneous vasoconstriction $(3,8,9)$. In our previous paper we demonstrated that inhibition of the DMH increased survival but did not change iBAT thermogenesis or cutaneous vasoconstriction (3). Therefore, while locomotor and non-locomotor components of heat accumulation from MDMA are approximately equal, inhibition of locomotion alone is sufficient to prevent hyperthermia and mortality from MDMA. Furthermore, MDMA users cannot control changes in non-shivering thermogenesis or cutaneous blood flow. They can however volitionally decrease or stop locomotion. While it seems intuitive that locomotion would contribute to heat production, our study is the first to conclusively show this with MDMA, and is contrary to what many authors have previously asserted (10-14).

The contribution of exercise to hyperthermia in users of MDMA is of particular clinical relevance, as many people use MDMA and stimulants to facilitate dancing in hot crowded environments (15). This may be why the majority of published cases of hyperthermia from MDMA continue to occur in persons at dance venues. An important question arising from this is why users of MDMA don't stop exercising when their core temperature becomes elevated. Under normal conditions in rodents and humans, exhaustion develops when core temperatures reach a critical threshold (16). In humans this is $\sim 40^{\circ} \mathrm{C}$ (17) while in rodents it is between $41-42^{\circ} \mathrm{C}$ (18). Exhaustion is thought to be a protective mechanism preventing heat stroke (16). Therefore drugs that prevent exhaustion may also increase the risk of developing drug-induced hyperthermia. It has been previously shown that drugs that increase central concentrations of dopamine and norepinephrine (NE), in both rats and humans, delay the development of exhaustion in a warm environment (19-21). Further research is needed to determine if MDMA, which also increases extracellular concentrations of dopamine and NE $(22,23)$, prevents exertional-related exhaustion and thereby increases the risk for developing heat stroke. 
The mechanism by which MDMA activates neurons in the DMH is not currently known, but may involve monoaminergic receptors. Studies where monoamine receptors antagonists have been systemically administered have shown that $\mathrm{D}_{1}$, alpha- $1,5 \mathrm{HT}-2_{\mathrm{A}}$ receptor antagonists block hyperthermia and locomotion produced by MDMA (24-27). Of these, alpha- 1 and $5-\mathrm{HT}-2_{\mathrm{A}}$ receptors within the DMH are strong candidates. Within the hypothalamus the DMH region has one of the highest concentrations of NE (28), and receives afferents from many brain stem NE groups, including the locus coeruleus (29). The $\mathrm{DMH}$ is also richly innervated by serotonergic fibers originating in the median raphe and midbrain dorsal raphe nucleus (30-32). In addition, the DMH contains $5-\mathrm{HT}_{2 \mathrm{~A}}$ receptors $(33,34)$ and has high concentrations of both serotonin and NE transporters (35). We are currently working on studies addressing both of these possibilities.

An important implication of our research is that the main hypothalamic contribution to the development of hyperthermia from MDMA is locomotion. While MDMA is known to increase non-shivering thermogenesis through $\mathrm{BBAT}$, and to decrease heat dissipation via cutaneous vasoconstriction - these effects are not mediated by the hypothalamus. Our data, and that of other labs, suggest that these effects are mediated at the level of the spinal cord or in the periphery $(3,36)$. Madden and Morrison (2006) have shown that serotonin receptors in the intermediolateral region of the spinal cord augment sympathetic responses evoked by local injections of the glutamate agonist n-methyl-d-aspartate (37). MDMA is known to increase the release of serotonin in various brain regions, and through its effects on serotonin $2 \mathrm{~A} / 2 \mathrm{C}$ receptors increase the release of glutamate (38); to date however, the effect of MDMA augmenting glutamate release has only been demonstrated in the hippocampus (38). Whether similar effects may be occurring within the spinal cord to facilitate iBAT thermogenesis and possibly cutaneous vasoconstriction requires further study. MDMA may also affect iBAT and cutaneous blood flow by increasing circulating concentrations of NE. MDMA causes significant increases in plasma concentrations of NE (39), which may cause alpha-1 mediated vasoconstriction. MDMA also causes increases in plasma free fatty acids, which in combination with NE may increase non-shivering thermogenesis in iBAT and skeletal muscle (40).

In conclusion, locomotion mediated by neurons in the $\mathrm{DMH}$ is an important contributor to the development of hyperthermia from MDMA. Determining the mechanisms by which MDMA activates neurons in the DMH may lead to a better understanding of how MDMA causes exertional heat stroke.

\section{Experimental Procedures}

\subsection{Animals}

Male adult Sprague-Dawley rats (weight $300 \pm 20 \mathrm{~g}$; Harlan, Indianapolis, IN) were used in this study. The Indiana University Animal Care and Use Committee approved all procedures. Experiments were performed using single-housed rats that were maintained in a $12 \mathrm{~h}$ light/dark cycle and fed ad libitum. Experiments were conducted on fully conscious rats between 10:00 a.m. and 4:00 p.m. in a specially designed environmental chamber (3). 


\subsection{Chemicals}

MDMA was generously provided by the NIH. All injection volumes were $1 \mathrm{ml} / \mathrm{kg}$ body weight. Muscimol (Sigma-Aldrich, St. Louis, MO) was dissolved in aCSF and stored at $-20^{\circ} \mathrm{C}$ until the time of the experiment.

\subsection{Surgery preparation}

Rats were anesthetized with 1.5-2\% isoflurane in oxygen; heart rate and oxygen saturation were monitored during surgery using a Pulse Oximeter monitor (LS1P-10R, Nonin, Plymouth, MN). We first placed bilateral guide cannulas targeting the $\mathrm{DMH}$, then we implanted a telemetric probe, and finally, we placed jugular venous catheters to allow for systemic drug administration. Rats were allowed to recover for at least 7 days after surgery before beginning treadmill experiments.

\subsection{Guide cannula surgical implantation}

Rats were placed in a stereotaxic apparatus with the incisor bar set at $3.3 \mathrm{~mm}$ below the interaural line. The skin overlying the dorsal surface of the skull was pretreated with lidocaine/epinephrine mixture, cut, and retracted followed by removal of soft tissue to expose the surface of the skull. The skull was treated with a $30 \%$ hydrogen peroxide solution using cotton-tipped applicators. This stopped bleeding, aided in sterility, and enhanced the visibility of sutures used as stereotaxic landmarks. Using a rotary tool (MiniMite Cordless 4.8V, Dremel, Racine, WI) equipped with a surgical carbide burr (DHP557, Miltex, Plainsboro, NJ), we made a small hole in the skull. We inserted the cannulas (26 gauge, Plastics One, Roanoke, VA) through the holes, and positioned them to target the DMH: AP $-3.1 \mathrm{~mm}$; LR $\pm 2.0 \mathrm{~mm}$; HD $-8.2 \mathrm{~mm}$ using bregma as a reference point (Paxinos et al., 1998). We used a 10-degree angle from the sagittal plane to avoid central sinus and to allow bilateral placement of two cannulas. We placed two jeweler's screws (size 80) into the skull to facilitate attachment of the cement cap and secured the cannulae using Vetbond glue (3M, St. Paul, MN) and cranioplastic cement. Dummy-wire cannulas were then inserted into the guides until the day of the experiment.

\subsection{Intravenous catheter implantation}

Rats were placed in a sterile surgery field in a dorsal recumbent position exposing the neck and shoulder area. A small longitudinal incision was made rostral to the clavicle and the jugular vein was dissected and ligated. We inserted a catheter, constructed of $3.5 \mathrm{~cm}$ Silastic tubing (508-007, Dow Corning, Midland, MI) connected to $10 \mathrm{~cm}$ of Tygon tubing (Small Parts Inc., Miami FL,) with $1 \mathrm{~cm}$ of PE-50 tubing (Plastics One). The catheter was filled with saline and inserted Silastic end first, approximately $3 \mathrm{~cm}$ into the vein. We then routed the catheter subcutaneously, exteriorizing it at the dorsal neck area. The catheter was flushed, capped with a metal plug, and secured to the skin with sutures.

\subsection{Temperature telemetric probe implantation}

For the measurement of core body temperature, TA-F40 telemetric transmitters (DSI, St. Paul, MN) were placed intraperitoneally via a $2 \mathrm{~cm}$-long longitudinal medial skin incision and muscular wall incision at the linea alba. Following insertion of the transmitter into the 
abdominal cavity and surgical closure, rats were returned to their home cage for at least 1 week before beginning treadmill familiarization.

\subsection{Treadmill familiarization}

Prior to experiments, rats were familiarized for at least 5 days to running on a motorized rodent treadmill (Columbus Instruments, Columbus, $\mathrm{OH}$ ). Rats ran each day for $5 \mathrm{~min}$ at a zero incline and each day the speed was progressively increased to a maximum, by day 5 , of $18 \mathrm{~m} / \mathrm{min}$. Familiarization occurred at room temperature. Workloads of familiarization programs are not sufficient to induce training adaptations (41), but allow the rats to become accustomed treadmill running. A mild electric stimulus at the back of the treadmill chamber promoted the learning of running behavior.

\subsection{Selection of speed for treadmill study}

To find the appropriate speed for treadmill study in MDMA experiments we considered average locomotor responses to MDMA itself. In a Raturn ${ }^{\circledR}$ (BASi, LaFayette, IN) cage, the cage we used in our most recent study (3), rats are connected by a tether to a switch which activates the motor to rotate the bowl in the direction opposite to the movement of the animal. The time when the motor is activated can be recalculated to the number of rotations that the bowl makes to counteract the run of the animal. Considering the radius of the trajectory that the animal runs on average, we can estimate the speed of locomotion. In our experiments we have shown that peak locomotion between 25 and $30 \mathrm{~min}$ after injection of $7.5 \mathrm{mg} / \mathrm{kg}$ MDMA measured in Raturn ${ }^{\circledR}$ cage was approximately 12.5 rotations per min (3). With the diameter of a circle run by the rat, which is defined by the diameter of the bowl at the level of bedding, being $\sim 22 \mathrm{~cm}$, we can estimate the speed as $\mathrm{n} * 0.22 * 12.5=8.6 \mathrm{~m} / \mathrm{min}$. In another previously published study using telemetric transmitters (Data Sciences Inc.) in standard rat cages, the locomotion at $30 \mathrm{~min}$ after a dose of MDMA (7.5 mg/kg, i.p.) was approximately 20 units (14). As the manufacturer calibrates the system with 1 unit to equal $\sim 1 \mathrm{~cm} / \mathrm{sec}$, the average speed is equivalent to approximately $12 \mathrm{~m} / \mathrm{min}$ (14). For the studies in this paper with MDMA we chose a treadmill speed of $10 \mathrm{~m} / \mathrm{min}$, which falls between our two previous studies $(3,14)$.

\subsection{Effect of inhibition of neuronal activity in the DMH on body temperature during running with and without MDMA}

The day before testing the rats were brought to experimental room and left overnight. To avoid the consequences of potential heat stroke, rats were tested only once. On the day of testing the cage with the rat was placed inside the environmental chamber and the animal was acclimated to the $32^{\circ} \mathrm{C}$ for $\sim 60 \mathrm{~min}$. Dummy-wire cannulas were then removed from guide cannulas, and microinjectors primed to deliver the appropriate injectate, were inserted into guide cannulas. Rats were randomized to one of four groups ( $n=5$ per group). Rats received pretreatment with either bilateral microinjections into the DMH of aCSF or muscimol then half got either a slow systemic injection of saline or MDMA $(7.5 \mathrm{mg} / \mathrm{kg}$, i.v.). After acclimation, the microinjection pump was activated for $30 \mathrm{sec}$ to deliver $100 \mathrm{nl}$ of the aCSF or muscimol. Two min later the microinjectors were removed from the guide cannulas, and the flow was checked. Five min after the microinjection, rats received systemic injections of either MDMA or saline, and were immediately placed on the belt of 
treadmill (Time 0 ) and the belt was advanced to $10 \mathrm{~m} / \mathrm{min}$. The rats were continuously monitored; when the body temperature reached $41^{\circ} \mathrm{C}$ the animal was immediately removed from the treadmill, and sacrificed by an overdose of Nembutal ( $100 \mathrm{mg} / \mathrm{kg}$, i.p.). This was done to prevent undue suffering of the animal as we had previously noted that rats given MDMA in a warm environment have a high mortality rate when body temperature exceeds $41^{\circ} \mathrm{C}(3)$.

\subsection{Identification of injection sites}

The rats were perfused transcardially with cold saline, followed by $4 \%$ paraformaldehyde. Brains were exteriorized, fixed overnight in $4 \%$ paraformaldehyde, then saturated in $23 \%$ sucrose in phosphate buffered saline, and frozen. Brain sections $(40 \mu \mathrm{m})$ were prepared using a cryocut (Leica 1850). The microinjection sites were determined by an observer who was "blind" to the treatment group, in sections stained with Neutral Red using anatomical landmarks according to rat brain atlas (42). The confirmation of injection sites is shown in Figure 1C.

\subsection{Data analysis and statistical procedures}

Statistical analyses and graphing were performed using Prism (Graphpad Software, San Diego, CA) software. Analyses requiring between-group comparisons were performed using analysis of variance (ANOVA) with a least significant difference (LSD) post hoc test where indicated. Significance was defined as a $p<0.05$. Values are presented as means \pm SEM.

\section{Acknowledgements}

Research reported in this publication was supported by the National Institute on Drug Abuse of the NIH under award number R01DA026867 and by a Project Development Team within the ICTSI NIH/NCRR Grant number UL1TR001108. Furthermore, this work was conducted in a facility constructed with support from the National Center for Research Resources, of the NIH under award number C06 RR015481-010. The content is solely the responsibility of the authors and does not necessarily represent the official views of the NIH.

\section{Abbreviations}

MDMA 3,4-methylenedioxymethamphetamine

DMH dorsomedial hypothalamus

NE norepinephrine

D $\quad$ dopamine 1 receptor

5-HT-2 $\quad$ serotonin $2 \mathrm{~A}$ receptor

\section{References}

1. Duarte JA, Leao A, Magalhaes J, Ascensao A, Bastos ML, Amado FL, Vilarinho L, Quelhas D, Appell HJ, Carvalho F. Strenuous exercise aggravates MDMA-induced skeletal muscle damage in mice. Toxicology. 2005; 206(3):349-58. Epub 2004/12/14. doi: S0300-483X(04)00418-4 [pii] 10.1016/j.tox.2004.07.012. PubMed PMID: 15588925. [PubMed: 15588925]

2. Tao R, Shokry IM, Callanan JJ, Adams HD, Ma Z. Mechanisms and environmental factors that underlying the intensification of 3,4-methylenedioxymethamphetamine (MDMA, Ecstasy)-induced 
serotonin syndrome in rats. Psychopharmacology (Berl). 2014 doi: 10.1007/s00213-014-3759-z. PubMed PMID: 25300903.

3. Zaretsky DV, Zaretskaia MV, Durant PJ, Rusyniak DE. Inhibition of the dorsomedial hypothalamus, but not the medullary raphe pallidus, decreases hyperthermia and mortality from MDMA given in a warm environment. Pharmacol Res Perspect. 2014; 2(2):e00031. doi: 10.1002/ prp2.31. PubMed PMID: 24765530; PubMed Central PMCID: PMC3994179. [PubMed: 24765530]

4. Nakamura K, Morrison SF. Central efferent pathways for cold-defensive and febrile shivering. The Journal of Physiology. 2011; 589(14):3641-58. doi: 10.1113/jphysiol.2011.210047. [PubMed: 21610139]

5. DiMicco JA, Samuels BC, Zaretskaia MV, Zaretsky DV. The dorsomedial hypothalamus and the response to stress: part renaissance, part revolution. Pharmacol Biochem Behav. 2002; 71(3):46980. [PubMed: 11830181]

6. Almeida MC, Steiner AA, Branco LG, Romanovsky AA. Neural substrate of cold-seeking behavior in endotoxin shock. PLoS One. 2006; 1:e1. doi: 10.1371/journal.pone.0000001. PubMed PMID: 17183631; PubMed Central PMCID: PMCPMC1762328. [PubMed: 17183631]

7. Rusyniak DE, Zaretskaia MV, Zaretsky DV, DiMicco JA. Microinjection of muscimol into the dorsomedial hypothalamus suppresses MDMA-evoked sympathetic and behavioral responses. Brain Res. 2008; 1226:116-23. [PubMed: 18586013]

8. Blessing WW, Seaman B, Pedersen NP, Ootsuka Y. Clozapine reverses hyperthermia and sympathetically mediated cutaneous vasoconstriction induced by $3,4-$ methylenedioxymethamphetamine (ecstasy) in rabbits and rats. J Neurosci. 2003; 23(15):6385-91. PubMed PMID: 12867524. [PubMed: 12867524]

9. Blessing WW, Zilm A, Ootsuka Y. Clozapine reverses increased brown adipose tissue thermogenesis induced by 3,4-methylenedioxymethamphetamine and by cold exposure in conscious rats. Neuroscience. 2006; 141(4):2067-73. PubMed PMID: 16814930. [PubMed: 16814930]

10. Dafters RI. Hyperthermia following MDMA administration in rats: effects of ambient temperature, water consumption, and chronic dosing. Physiol Behav. 1995; 58(5):877-82. [PubMed: 8577883]

11. Docherty JR, Green AR. The role of monoamines in the changes in body temperature induced by 3,4-methylenedioxymethamphetamine (MDMA, ecstasy) and its derivatives. Br J Pharmacol. 2010; 160(5):1029-44. Epub 2010/07/02. doi: BPH722 [pii] 10.1111/j.1476-5381.2010.00722.x. PubMed PMID: 20590597. [PubMed: 20590597]

12. Green AR, O'Shea E, Colado MI. A review of the mechanisms involved in the acute MDMA (ecstasy)-induced hyperthermic response. Eur J Pharmacol. 2004; 500(1-3):3-13. PubMed PMID: 15464016. [PubMed: 15464016]

13. O'Shea E, Escobedo I, Orio L, Sanchez V, Navarro M, Green AR, Colado MI. Elevation of ambient room temperature has differential effects on MDMA-induced 5-HT and dopamine release in striatum and nucleus accumbens of rats. Neuropsychopharmacology. 2005; 30(7):1312-23. Epub 2005/02/03. doi: 10.1038/sj.npp.1300673. PubMed PMID: 15688085. [PubMed: 15688085]

14. Rusyniak DE, Zaretskaia MV, Zaretsky DV, DiMicco JA. 3,4-Methylenedioxymethamphetamineand 8-hydroxy-2-di-n-propylamino-tetralin-induced hypothermia: role and location of 5hydroxytryptamine 1A receptors. J Pharmacol Exp Ther. 2007; 323(2):477-87. Epub 2007/08/19. doi: jpet.107.126169 [pii] 10.1124/jpet.107.126169. PubMed PMID: 17702902. [PubMed: 17702902]

15. TF, MtB; Engels, RC. "Partying" hard: party style, motives for and effects of MDMA use at rave parties. Subst Use Misuse. 2005; 40(9-10):1479-502. doi: 10.1081/JA-200066822. PubMed PMID: 16048829. [PubMed: 16048829]

16. Noakes TD. Fatigue is a Brain-Derived Emotion that Regulates the Exercise Behavior to Ensure the Protection of Whole Body Homeostasis. Front Physiol. 2012; 3:82. doi: 10.3389/fphys. 2012.00082. PubMed PMID: 22514538; PubMed Central PMCID: PMC3323922. [PubMed: 22514538]

17. González-Alonso J, Teller C, Andersen SL, Jensen FB, Hyldig T, Nielsen B. Influence of body temperature on the development of fatigue during prolonged exercise in the heat. J Appl Physiol. 1999; 88(3):1032-9. [PubMed: 10066720] 
18. Walters TJ, Ryan KL, Tate LM, Mason PA. Exercise in heat is limited by a critical internal temperature. J Appl Physiol. 2000; 89:799-806. [PubMed: 10926668]

19. Roelands B, Hasegawa H, Watson P, Piacentini MF, Buyse L, De Schutter G, Meeusen RR. The effects of acute dopamine reuptake inhibition on performance. Med Sci Sports Exerc. 2008; 40(5): 879-85. Epub 2008/04/15. doi: 10.1249/MSS.0b013e3181659c4d. PubMed PMID: 18408610. [PubMed: 18408610]

20. Roelands B, Meeusen R. Alterations in central fatigue by pharmacological manipulations of neurotransmitters in normal and high ambient temperature. Sports Med. 2010; 40(3):229-46. [PubMed: 20199121]

21. Watson P, Hasegawa H, Roelands B, Piacentini MF, Looverie R, Meeusen R. Acute dopamine/ noradrenaline reuptake inhibition enhances human exercise performance in warm, but not temperate conditions. The Journal of physiology. 2005; 565:873-83. Pt 3. Epub 2005/04/16. doi: 10.1113/jphysiol.2004.079202. PubMed PMID: 15831540; PubMed Central PMCID: PMC1464564. [PubMed: 15831540]

22. Gudelsky GA, Yamamoto BK. Actions of 3,4-methylenedioxymethamphetamine (MDMA) on cerebral dopamineric, serotonergic and cholinergic neurons. Pharmacol Biochem Behav. 2007; 90(2):198-207. doi: S0091-3057(07)00313-9 [pii] 10.1016/j.pbb.2007.10.003. PubMed PMID: 18035407. [PubMed: 18035407]

23. Rothman RB, Baumann MH, Dersch CM, Romero DV, Rice KC, Carroll FI, Partilla JS. Amphetamine-type central nervous system stimulants release norepinephrine more potently than they release dopamine and serotonin. Synapse. 2001; 39(1):32-41. PubMed PMID: 11071707. [PubMed: 11071707]

24. Daniela E, Brennan K, Gittings D, Hely L, Schenk S. Effect of SCH 23390 on (+/-)-3,4methylenedioxymethamphetamine hyperactivity and self-administration in rats. Pharmacol Biochem Behav. 2004; 77(4):745-50. doi: 10.1016/j.pbb.2004.01.008. PubMed PMID: 15099919. [PubMed: 15099919]

25. Fantegrossi WE, Godlewski T, Karabenick RL, Stephens JM, Ullrich T, Rice KC, Woods JH. Pharmacological characterization of the effects of 3,4-methylenedioxymethamphetamine ("ecstasy") and its enantiomers on lethality, core temperature, and locomotor activity in singly housed and crowded mice. Psychopharmacology (Berl). 2003; 166(3):202-11. PubMed PMID: 12563544. [PubMed: 12563544]

26. Kehne JH, Ketteler HJ, McCloskey TC, Sullivan CK, Dudley MW, Schmidt CJ. Effects of the selective 5-HT2A receptor antagonist MDL 100,907 on MDMA-induced locomotor stimulation in rats. Neuropsychopharmacology. 1996; 15(2):116-24. [PubMed: 8840347]

27. Selken J, Nichols DE. Alpha1-adrenergic receptors mediate the locomotor response to systemic administration of (+/-)-3,4-methylenedioxymethamphetamine (MDMA) in rats. Pharmacol Biochem Behav. 2007; 86(4):622-30. Epub 2007/03/17. doi: S0091-3057(07)00077-9 [pii] 10.1016/j.pbb.2007.02.006. PubMed PMID: 17363047. [PubMed: 17363047]

28. Bernardis LL, Bellinger LL. The dorsomedial hypothalamic nucleus revisited: 1986 update. Brain Res. 1987; 434(3):321-81. PubMed PMID: 3300862. [PubMed: 3300862]

29. Moore RY, Bloom FE. Central catecholamine neuron systems: anatomy and physiology of the dopamine systems. Annu Rev Neurosci. 1978; 1:129-69. PubMed PMID: 756202. [PubMed: 756202]

30. Jacobs BL, Wise WD, Taylor KM. Differential behavioral and neurochemical effects following lesions of the dorsal or median raphe nuclei in rats. Brain Res. 1974; 79(3):353-61. Epub 1974/10/25. doi: 0006-8993(74)90433-8 [pii]. PubMed PMID: 4420173. [PubMed: 4420173]

31. Palkovits M, Saavedra JM, Jacoboqitz DM, Kizer JS, Zaborszky L, Brownstein MJ. Serotonergic innervation of the forebrain: effect of lesions on serotonin and tryptophan hydroxylase levels. Brain Res. 1977; 130(1):121-34. Epub 1977/07/08. PubMed PMID: 884514. [PubMed: 884514]

32. Steinbusch HW. Distribution of serotonin-immunoreactivity in the central nervous system of the rat-cell bodies and terminals. Neuroscience. 1981; 6(4):557-618. Epub 1981/01/01. doi: 0306-4522(81)90146-9 [pii]. PubMed PMID: 7017455. [PubMed: 7017455]

33. Frankfurt M, Mendelson SD, McKittrick CR, McEwen BS. Alterations of serotonin receptor binding in the hypothalamus following acute denervation. Brain Res. 1993; 601(1-2):349-52. 
Epub 1993/01/22. doi: 0006-8993(93)91735-B [pii]. PubMed PMID: 8431786. [PubMed: 8431786]

34. Zhang L, Ma W, Barker JL, Rubinow DR. Sex differences in expression of serotonin receptors (subtypes 1A and 2A) in rat brain: a possible role of testosterone. Neuroscience. 1999; 94(1):2519. PubMed PMID: 10613515. [PubMed: 10613515]

35. Hoffman BJ, Hansson SR, Mezey É, Palkovits M. Localization and Dynamic Regulation of Biogenic Amine Transporters in the Mammalian Central Nervous System. Front Neuroendocrinol. 1998; 19(3):187-231. [PubMed: 9665836]

36. Ootsuka Y, Nalivaiko E, Blessing WW. Spinal 5-HT2A receptors regulate cutaneous sympathetic vasomotor outflow in rabbits and rats; relevance for cutaneous vasoconstriction elicited by MDMA (3,4-methylenedioxymethamphetamine, "Ecstasy") and its reversal by clozapine. Brain Res. 2004; 1014(1-2):34-44. PubMed PMID: 15212989. [PubMed: 15212989]

37. Madden CJ, Morrison SF. Serotonin potentiates sympathetic responses evoked by spinal NMDA. J Physiol. 2006; 577:525-37. Pt 2. PubMed PMID: 16973701. [PubMed: 16973701]

38. Anneken JH, Gudelsky GA. MDMA produces a delayed and sustained increase in the extracellular concentration of glutamate in the rat hippocampus. Neuropharmacology. 2012; 63(6):1022-7. doi: 10.1016/j.neuropharm.2012.07.026. PubMed PMID: 22842073; PubMed Central PMCID: PMC3437747. [PubMed: 22842073]

39. Sprague JE, Moze P, Caden D, Rusyniak DE, Holmes C, Goldstein DS, Mills EM. Carvedilol reverses hyperthermia and attenuates rhabdomyolysis induced by 3,4methylenedioxymethamphetamine (MDMA, Ecstasy) in an animal model. Crit Care Med. 2005; 33(6):1311-6. PubMed PMID: 15942349. [PubMed: 15942349]

40. Mills EM, Weaver KL, Abramson E, Pfeiffer M, Sprague JE. Influence of dietary fats on ecstasyinduced hyperthermia. Br J Pharmacol. 2007 PubMed PMID: 17533413.

41. Lambert MI, Noakes TD. Dissociation of changes in VO2 max, muscle QO2, and performance with training in rats. J Appl Physiol (1985). 1989; 66(4):1620-5. Epub 1989/04/01. PubMed PMID: 2732155. [PubMed: 2732155]

42. Paxinos, G.; Watson, C. The Rat Brain in Stereotaxic Coordinates. 4. Academic Press; New York: 1998. 


\section{Highlights}

- Decreases in MDMA-mediated hyperthermia caused by inhibiting neurons in the DMH are from reducing locomotion.

- Locomotion is largest contributor to heat accumulation from MDMA

- Neurons in the region of the DMH mediate locomotion from MDMA 

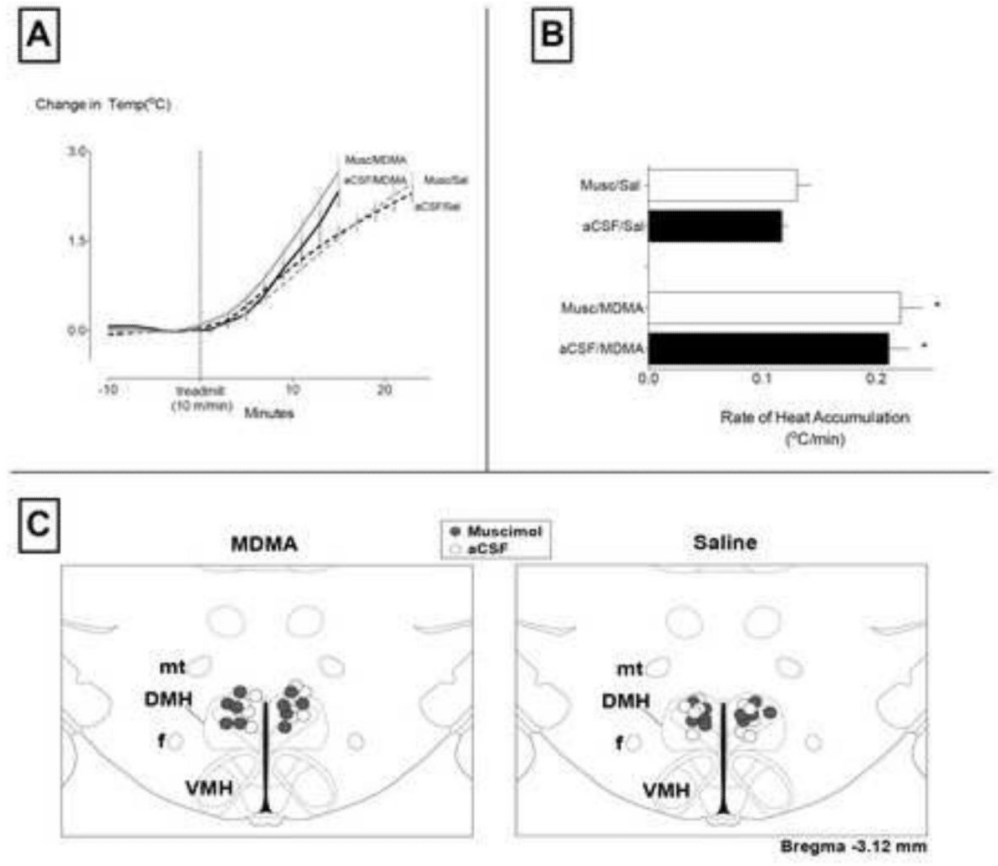

Figure 1.

A: Inhibition of the DMH does not suppress hyperthermia induced by running on a treadmill in rats administered 80pmol/100nm muscimol plus either $7.5 \mathrm{mg} / \mathrm{kg}$ MDMA or saline. Solid lines represent rats treated systemically with MDMA $(7.5 \mathrm{mg} / \mathrm{kg})$ and dotted lines rats treated systemically with saline. Black lines represent rats microinjected with aCSF and grey lines microinjected with muscimol $(80 \mathrm{pmol} / 100 \mathrm{nl})$. The data represents time points for each respective group (either saline or MDMA) where no animal had reached a body temperature of $41^{\circ} \mathrm{C}$.

$\mathrm{B}$ : The rates of heat accumulation in rats microinjected into the $\mathrm{DMH}$ with either muscimol (white columns) or aCSF (black columns) followed by the systemic administration of either saline (top columns) or MDMA (bottom columns). The rate was calculated as a slope of temperature increase during the linear portion of temperature increase between 6 and 14 min of running on the treadmill. * represents a difference $(p<0.05)$ in the rates of heat accumulation between rats treated with MDMA and their corresponding saline control C: A schematic of coronal brain section, adapted from the Paxinos and Watson (1998) atlas, with locations of injection sites. $\mathrm{DMH}=$ dorsal medial hypothalamus, $\mathrm{VMH}=$ ventromedial hypothalamus Microinjections of muscimol are denoted by filled circles and microinjections of aCSF by open circles. 